\title{
Learning to organize in free recall
}

\author{
LARAINE MASTERS GLIDDEN \\ Teachers College, Columbia University, New York, New York 10027
}

\begin{abstract}
A multitrial free recall study assessed the effects of learning-to-learn and learning-to-organize over experimental sessions. An experimental group (Group E) learned five successive lists on 5 successive days, whereas a control group (Group C) learned only two lists, on Day 1 and on Day 5 of Group E training. Results showed a learning-to-learn effect for Group E, but not for Group C. Subjective organization scores increased for both groups, indicating that the learning-to-organize effect reached an asymptote more quickly than the learning-to-learn effect.
\end{abstract}

The learning-to-learn effect has been well established across many tasks and species. Although there was some controversy concerning its occurrence in the free recall situation (e.g., Murdock, 1960, found no increase in performance over successive lists.), a number of studies have obtained the effect (Dallett, 1963; Mayhew, 1967; Meyer \& Miles, 1953; Tulving, McNulty, \& Ozier, 1965). In addition, both the Tulving, et al. and Mayhew experiments investigated a learning-to-organize phenomenon by measuring changes in subjective organization (SO) as a function of learning sessions. In both studies, learning to organize was demonstrated as SO increased with an increase in number of prior lists learned.

Both of these studies, however, contain a serious methodological problem: no control groups were included to assess the extent of (1) warm-up effects and (2) effects of improvement over time, rather than with practice. In the Tulving, McNulty, and Ozier study warm-up is a reasonable alternative explanation since three successive lists were given with only a two minute interval between lists. In the Mayhew study, two lists were given on each of 3 successive days and SO scores significantly increased both within and between sessions. Thus, the increases in this study could be attributed to a combination of warm-up and time effects.

The present experiment was designed to correct this problem. An experimental group (Group E) received free recall learning sessions on five successive days while a control group (Group C) received training on only Day 1 and Day 5. Thus, if differences in recall and SO occurred between the two groups on Day 5, they could be attributed directly to the effects of practice.

\section{METHOD}

\section{Subjects}

The subjects were 40 undergraduates who were paid for their

This study was partially supported by a grant from the Research Board of Clarkson College of Technology. Thanks go to Joan M. Roemer for helping to run subjects. The manuscript is sponsored by Keith G. Scott who takes full editorial responsibility for it.

Requests for reprints should be sent to the author, Box 89 , Teachers College, Columbia University, New York, New York 10027. participation in the experiment. Twenty subjects were randomly assigned to Group E and 20 were assigned to Group C. The subjects in Group E learned five different 10 -item free recall lists, one list on each of 5 successive days, while subjects in Group C learned only two lists, on Day 1 of Group E training and on Day 5 of Group E training.

\section{Design}

The five recall lists were arranged in five sequences so that each list occupied a different position in each sequence. Four subjects in Group E were randomly assigned to each sequence. Thus an equal number of subjects received each list on a given day. Each subject in Group $\mathrm{C}$ was yoked to a subject in Group $\mathrm{E}$ to determine which list he would receive on Day 1 and Day 5 . Thus, list treatments were completely comparable for the two groups.

Further, the order of items within lists was arranged by a Bugelski Latin square. Thus, each stimulus appeared in each serial position once and was preceded and followed by each other stimulus only once throughout 10 free recall trials. These 10 different list orders were then arranged by another Latin square to determine sequence of list orders within a session. Each Group E subject and his Group C yoke were then randomly assigned to one of these sequences for each training session.

The five free recall lists were composed of CVC stimuli scaled by Glaze (1928) for meaningfulness. The 50 items were assigned to lists by equating them for meaningfulness and formal similarity. The mean Glaze scores were of moderate level, ranging from 44.8 to 50.5 . The formal similarity in each list was equated so that each list contained 20 different letters of which 10 appeared once and another 10 appeared twice. The stimuli were typewritten in upper case and projected as slides at a rate of $1.5 \mathrm{sec} / \mathrm{item}$. The temporal in tervals were automatically timed by a Hunter decade interval timer and a Hunter interval cycler.

\section{Procedure}

The subjects were tested individually. They were given standard free recall instructions followed by two practice trials with digits prior to the 10 experimental trials. Each study trial was followed by a 60 -sec free recall test and a 10 -sec intertrial interval. All Group $\mathrm{E}$ subjects received their successive sessions within 20-30 h of the previous session. All Group $\mathrm{C}$ subjects received their Day 5 session within $90-102 \mathrm{~h}$ of their Day 1 session. Only three subjects were discarded because of failure to complete all experimental sessions; two of them were Group E subjects.

\section{RESULTS}

\section{Free Recall Scores}

The number of correct responses was determined for 
each subject for each trial. Table 1 presents these mean free recall scores of Groups $\mathrm{E}$ and $\mathrm{C}$. Both groups show increments across sessions with Group $E$ showing an apparently larger increase from Session 1 to Session 5 than Group C. A groups (E vs. C) by sessions (1 vs. 5) by trials $(1-10)$ analysis of variance was performed on these data. ${ }^{1}$ The main effect of groups was not significant, but the main effects of both sessions $[F(1,38)=21.02$, $\mathrm{p}<.01)$, and trials $[\mathrm{F}(9,342)=171.30, \mathrm{p}<.01]$ and the Groups by Sessions interaction $[F(1,38)=10.04$, $p<.01]$ were significant. Because of the significant interaction, tests of simple effects were done. The only significant simple effect was that of sessions for Group E $[F(1,38)=30.27, p<.01)$ indicating that there was a significant difference in free recall scores across sessions for Group E, but not for Group C.

\section{Subjective Organization}

SO was measured bidirectionally by the formula: obs $/ \mathrm{c}-1-2 \mathrm{c} / \mathrm{hk}$; (obs $=$ number of intertrial sequential consistencies; $\mathrm{c}=$ items in common between Trial $\mathrm{N}$ and Trial $\mathrm{N}+1, \mathrm{~h}=$ items correct on Trial $\mathrm{N}, \mathrm{k}=$ items correct on Trial $\mathrm{N}+1$ ). Table 1 presents the $\mathrm{SO}$ data for Groups $\mathrm{E}$ and $\mathrm{C}$ for successive sessions. For both Groups, SO seems to increase about equally from first to last session. A groups (2) by sessions (2) by trials (9) analysis of variance was performed on these data. This analysis yielded significant main effects for sessions $[\mathrm{F}(1,38)=7.35, \mathrm{p}<.025]$ and trials $[\mathrm{F}(8,304)=2.71$, $\mathrm{p}<.01]$, but not for groups. Thus, although increases in SO occurred, they occurred equally for Groups $\mathrm{C}$ and $\mathrm{E}$. To test whether this increase in Group $\mathrm{C}$ was a result of the long time lag between first and last session for this group, an analysis of variance was performed on the SO data using Session 2 for Group E rather than Session 5. (Note that this comparison is not strictly valid since Group C subjects, on their last session, were matched for list treatments with Session 5 Group E subjects). This analysis also showed significant main effects for sessions $[\mathrm{F}(1,38)=5.36, \mathrm{p}<.05]$ and trials $[\mathrm{F}(8,304)=3.12$, $\mathrm{p}<.01]$, but not for groups. Thus, the increase in SO that occurred for Group $\mathrm{C}$ was not due to the longer time interval. It also occurred in Group $\mathrm{E}$ whose subjects only had about $24 \mathrm{~h}$ between sessions.

\section{Serial Position}

SO measures a type of organization which does not include all strategies that subjects may learn to use during extended practice with the free recall task. Of interest, also, were changes that might be reflected by an analysis of serial position effects. Classic recency and primacy effects were obtained which yielded a significant main effect for serial position $[\mathrm{F}(9,342)=$ $12.74, \mathrm{p}<.001$ ] in a groups (2) by sessions ( 2 ) by serial
Table 1

Mean Free Recall and Subjective Organization Scores for Experimental and Control Groups in Each Session

\begin{tabular}{cccccc}
\hline & \multicolumn{2}{c}{ Iree Recall } & & \multicolumn{2}{c}{$\begin{array}{c}\text { Subjective } \\
\text { Organization }\end{array}$} \\
\cline { 2 - 3 } \cline { 5 - 6 } Session & Group E & Group C & & Group E & Group C \\
\hline 1 & 6.53 & 7.05 & & .02 & .03 \\
2 & 7.11 & - & & .06 & - \\
3 & 7.16 & - & & .10 & - \\
4 & 7.64 & - & & .10 & - \\
5 & 7.90 & 7.30 & .11 & .10 \\
\hline
\end{tabular}

position (10) analysis of variance, but it did not interact with either groups or sessions, indicating no significant changes in serial position effects as a result of practice.

\section{DISCUSSION}

Both learning-to-learn and learning-to-organize effects were obtained for Group E. For Group C, however, no significant increase occurred in free recall. Thus, the learning-to-learn effect obtained in this experiment cannot be attributed to either warm-up effects or temporal interval since these variables were controlled for by Group C. Also of interest is that SO for Group C increased significantly over time without additional practice sessions. This fact, in conjunction with the means for SO in Group E reaching an asymptote by Session 3, suggests that the learning-to-organize effect does not completely parallel the learning-to-learn effect since subjects continue to improve in free recall after they have stopped improving in SO. Whatever improvements are occurring in free recall performance thereafter are not a function of learning to organize as measured by SO. Neither are they a function of changes analyzable in serial position curves, since no significant changes in this variable were found across sessions. Thus, although a genuine learning-to-learn effect, independent of both warm-up and increases over time has been demonstrated, this effect is not completely attributable to learning-to-organize effects which seem to reach an asymptote with less practice.

\section{REFERENCES}

Dallett, K. M. Practice effects in free and ordered recall. Journal of Experimental Psychology, 1963, 66, 65-71.

Glaze, J. A. The association value of nonsense syllables. Journal of Genetic Psychology, 1928, 35, 255-269.

Mayhew, A. J. Interlist changes in subjective organization during free recall learning. Journal of Experimental Psychology $1967,74,425-430$.

Meyer, D. R., \& Miles, R. C. Intralist-interlist relations in verbal learning. Journal of Experimental Psychology, 1953, 45, 109-115.

Murdock, B. B., Jr. The immediate retention of unrelated words. Journal of Experimental Psychology, 1960, 60, 222-234.

Tulving, E., McNulty, J. A., \& Ozier, M. Vividness of words and learning-to-learn in free recall learning. Canadian Journal of Psychology, 1965, 19, 242-252.

\section{NOTE}

1. All analyses on free recall scores were also performed on arcsin transformed data. Since patterns of significance were the same in all cases, results will be presented in terms of the nontransformed scores.

(Received for publication November 11, 1974.) 